\title{
Pengaruh Budaya Kerja, Kemampuan dan Komitmen Terhadap Kinerja Dosen Perguruan Tinggi di Kabupaten Maros
}

\author{
M. Fadhil ${ }^{1)}$, Muhammad Ashoer ${ }^{2}$ \\ ${ }^{1,2)}$ Universitas Muslim Indonesia, muhammad.fadhil@umi.ac.id ${ }^{1}$, muhammad.ashur@umi.ac.id $^{2}$
}

\section{ARTICLES}

INFORMATION

ABSTRACT

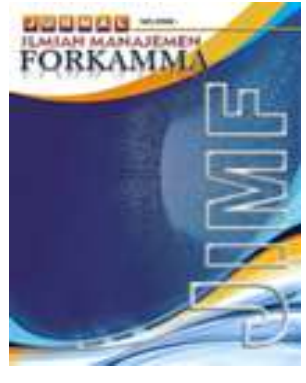

\section{JURNAL ILMIAH MANAJEMEN FORKAMMA}

Vol.3, No. 2, Maret 2020

Halaman : $161-169$

(c) LPPM \& FORKAMMA

Prodi Magister Manajemen

UNVERSITAS PAMULANG

ISSN (online) : 2599-171X

ISSN (print) : :2598-9545

Keyword :

Kinerja, budaya kerja,

kemampuan, komitmen

JEL. classification :

O15,

Contact Author :

PRODI

MAGISTER MANAJEMEN \& FORKAMMA UNPAM

JL.Surya Kencana No.1 Pamulang

Tangerang Selatan - Banten

Telp. (021) 7412566, Fax (021) 7412491 Email :

jurnalforkamma.unpam@gmail.com
Penelitian ini bertujuan untuk mengidentifikasi dan menganalisis secara simultan pengaruh budaya, kemampuan dan komitmen terhadap kinerja dosen di universitas di Maros. Kami juga mengukur prediktor mana yang memiliki dampak terbesar pada kinerja. Penelitian ini menggunakan data primer melalui total populasi 191 orang dengan metode sampel yaitu sampel yang mewakili jumlah total dosen di perguruan tinggi di Maros adalah 129 orang, sedangkan periode penelitian yang dilakukan mulai September, Oktober dan November 2018. Penelitian ini menggunakan data deskriptif dan analisis statistik. Hasil uji-F berdasarkan regresi berganda untuk membenarkan dan memverifikasi hipotesis. Ini ditunjukkan oleh F-rasio dan probabilitas 74,409 dengan kurang dari 0,05 atau nilai $P<0,05$, dengan kata lain menerima hipotesis. Dari ketiga variabel yang dipilih, maka nilai indeks menunjukkan bahwa kemampuan (X2) adalah aspek terkuat dengan nilai 0,322, kemudian komitmen (X3) dengan nilai 0,301 dan budaya kerja dengan nilai 0,228. Temuan ini menunjukkan bagaimana budaya kerja, kemampuan dan komitmen dapat meningkatkan kinerja dosen di Kabupaten Maros.

This study purposes to identify and analyze simultaneously the influence of cultural, ability and commitment on performance of lecturers at universities in Maros. We also measure which predictor has the greatest impact on performance. This research used primary data through total population of 191 people by the method of sample is a sample that represents the total number of lecturers at universities in Maros is 129 people, while a period of research conducted from September, October and November 2018. This study uses descritive data and statistical analysis. The F-test result based on multiple regression to justify and verified the hypothesis. It is the show by F-ratio and probability of 74.409 with less than 0.05 or $P$ value $<0.05$, in other words accepted hypothesis. Of the three variables are selected, then the value of index showed that the ability (X2) is the strongest aspect with a value of 0.322 , then the commitment (X3) with a value of 0.301 and work culture with the value of 0.228 . This founding indicates how work culture, ability and commitment can enhance the lecturer performance in Maros regency. 


\section{A. PENDAHULUAN}

Perkembangan peran lembaga pendidikan semakin pesat, ini ditandai pertumbuhan kuantitas jumlah Perguruan Tinggi Negeri (PTN) dan Perguruan Tinggi Swasta (PTS) di Indonesia. Konsekuensinya, lembaga dituntut untuk konsisten dalam mengembankan aspek yang menunjang peningkatan kualitas kinerja tenaga pengajar. Kualitas sumber daya manusia seringkali ditengarai menjadi penyebab turunnya performa sebuah institusi. Suatu perguruan tinggi dianggap berhasil jika dapat meningkatkan sumber daya yang kompeten berdasarkan tugas, pokok, dan fungsinya dalam mencapai visi misi sebuah organisasi, khususnya institusi pendidikan. Armstrong (2016) memertegas dalam bahwa dalam era ekonomi pengetahuan, sumber daya manusia dalam mempromosikan pembangunan ekonomi dan kemajuan sosial dari peran tersebut menjadi semakin menonjol, dan keuntungan sumber daya manusia akan menjadi keunggulan kompetitif utama.

Membangun sebuah sistem manajemen sumber daya manusia yang ilmiah, efisien, dan memiliki tolak ukur (benchmark) dapat memaksimalkan efektivitas sumber daya manusia secara keseluruhan (Dessler, 2013). Universitas adalah basis utama inovasi pengetahuan nasional dan menumbuhkan semangat inovasi, dan inovasi adalah tempat lahir bakat yang penting dan merupakan sumber utama bakat kreatif tingkat tinggi. Institusi pendidikan tinggi juga harus meningkatkan kualitas sumber daya manusia, dan mengembangkan potensinya dalam rangka penguatan posisi daya saing universitas. Kualitas SDM perguruan tinggi dan universitas sangat tergantung pada peningkatan tingkat kualitas keseluruhan dan mekanisme manajemen sumber daya manusia (Handoko, 2012). Tetapi dalam mode manajemen SDM di era 5.0 ini, masih terdapat pelbagi masalah dan isu tertentu yang berrdampak negatif terhadap upaya peningkatan mutu SDM di perguruan tinggi.

Tenaga pengajar atau dosen adalah elemen terpenting yang menentukan kualitas pendidikan dan luaran lulusan yang diciptakan oleh sebuah institusi, tanpa mengabaikan kualitas umum (selain dosen) itu sendiri (Cai dan Lin, 2006). Jika dosen memiliki kapabilitas yang mumpuni, maka secara langsung kualitas kampus juga akan ikut terdorong, dan sebaliknya, sesempurna bagaimanapun program pendidikan dan pengajaran yang direncanakan, jika tidak ditopang oleh dosen yang berkualitas, maka tujuan tersebut hanya akan berakhir dengan tidak memuaskan. Ini bersifat substansial, mengingat keduanya dibutuhkan dosen yang juga cukup berkualitas. Dengan memiliki dosen yang produktivitas tinggi, universitas dapat merumuskan kurikulum paling modern untuk memastikan output prestasi dan kualitas khusus. Untuk mencetak lulusan yang memiliki kemampuan kognitif, afektif maupun pisikomotorik, perguruan tinggi membutuhkan proses akademik dan sistem pengajaran yang terbaik. Dalam melaksanakan Tridharma Perguruan Tinggi, dosen dipengaruhi oleh budaya kerja institusi, dan perbedaan tersebut disebabkan oleh strategi kebijakan yang berbeda. Meskipun budaya kerja berbeda di setiap perguruan tinggi, tetapi tujuan sama yakni menciptakan tamatan yang memiliki integritas dan kapabilitas di bidang keilmuannya masing-masing. Tujuan penerapan budaya kerja pada setiap perguruan tinggi dalam rangka menciptakan lingkungan kerja yang kodusif dan meningkatkan etos kerja produktif.

Kemampuan dosen dapat dipengaruhi oleh sistem pendidikan dan pelatihan yang telah diperoleh, serta adanya inisiatif yang dimiliki dan pengalaman kerja yang dimiliki. Mengingat tugas dosen cukup berat, maka tidak mudah bagi Perguruan Tinggi khsusnya Perguruan Tinggi Swasta (PTS) menjaga konsistensi kualitas pekerjaan untuk periode waktu yang lama. Kondisi ini juga diperparah oleh kelemahan PTS dalam memberikan kesejahteraan dan meningkatkan sarana dan prasarana kampus. Di sisi lain, PTS tidak memiliki wewenang untuk menindak tegas seorang dosen apabila tidak menjalankan Tridahrma PT (pendidikan dan pengajaran, penelitian, dan pengabdian kepada 
mayarakat). Cukup ironis, mengingat kebanyakan PTS belum melihat peran vital komitmen dosen terhadap mutu universitas.

Beberapa penelitian mencatat bagaimana budaya kerja, kemampuan dan komitmen memengaruhi kualitas kinerja khususnya dosen. Sangadji dan Sopiah (2013) membuktikan bahwa budaya memiliki andil dalam peningkatan kepuasan dan kinerja dosen di Jawa Timur. Peterson dan Mets (dalam Hetty Murdiyani, 2010) juga menganggap bahwa komitmen dosen memberikan efek positif terhadap proses belajar mengajar, interaksi dengan mahasiswa, rekan kerja dan pimpinan. Selain itu, Bungai dan Perdana (2018) menambahkan bahwa komitmen dosen meningkatkan produktivitas dalam menjalankan Tridarma PT. Perilaku ini merupakan sebagian dari indikator keberhasilan pencapaian tujuan perguruan tinggi di Indonesia.

Fenomena perilaku tenaga pengajar di PTS Kabupaten Maros mengindikasikan bahwa yaitu Tridarma PT belum sepenuhnya diterapkan sebagai kewajiban pokok dosen. Permasalahan ini terjadi karena sebagian besar dosen memegang jabatan di instansi lain sehingga dalam pelaksanaan tanggung jawab sebagai dosen di perguruan tinggi tersebut belum sepenuhnya terlaksana. Dosen Perguruan Tinggi di Kabupaten Maros terdapat beberapa dosen selain sebagai pengajar di perguruan tinggi tersebut juga memegang jabatan internal struktural sehingga tanggung jawabnya semakin besar terhadap perguruan tinggi. Meskipun beberapa dosen telah memiliki sertifikasi namun ini belum sebanding jika dilihat dari aspek kedisiplinan kerja, kemampuan melaksanakan pekerjaaan yang dibebankan oleh perguruan tinggi dan komitmen terhadap perguruan tinggi, melaksanakan penelitian, pengembangan hasil penelitian yang dapat dinikmati oleh masyarakat dan sosialiasi kepada masyarakat.

\section{B. KAJIAN LITERATUR}

\section{Manajemen Sumber Daya Manusia}

Bontis (1996) menyatakan bahwa modal manusia merupakan keunggulan kompetitif yang berkelanjutan bagi organisasi dalam lingkungan bisnis yang terus berubah (ever-changing). Sebuah studi Khairuzzaman (2014) menyimpulkan bahwa, lebih dari sebelumnya, SDM dipandang lebih penting daripada teknologi baru atau sumber daya keuangan dan material. Karasteristik pekerjaan yang dinamis - terutama perkembangan teknologi, organisasi, dan persaingan ketat - mendorong organisasi berjuang untuk menarik dan mempertahankan pasokan karyawan yang sesuai dengan kebutuhan perusahaan. Armstrong (2016) berpendapat konsep manajemen SDM yang strategis menjadi semakin diperhitungkan dalam pengambilan keputusan. Di era ekonomi berbasis pengetahuan, penekanannya terletak pada karyawan yang dinilai sebagai aset utama untuk mencapai keunggulan kompetitif atau distincitive perusahaan. Peneliti lain juga menguatkan bahwa keputusan perusahaan dalam berinvestasi pada SDM dengan komitmen yang lebih besar dan turnover yang lebih rendah lebih efektif (Subramony, 2006). Andil individu dalam mengembangkan dan memajukan organisasi memerlukan sumber daya yang potensial, handal, kemandirian dan profesional agar dapat menghadapi lingkungan kerja yang statis dan dinamis.

\section{Budaya Kerja}

Budaya organisasi adalah strategi vital yang dapat dimaksimalkan oleh manajer untuk menentukan arah bisnis mereka (Yiing dan Ahmad, 2009). Budaya organisasi secara umum didefinisikan sebagai seperangkat nilai kunci, asumsi, pemahaman, dan norma yang ada di antara anggota organisasi (Daft, 2003). Ketetapan nilai dan norma ini menunjukkan cara tepat untuk saling berhubungan, sehingga mereka harus memberikan pemahaman yang sama kepada semua anggota organisasi dalam melakukan pekerjaan mereka (Saranya, 2014). Budaya organisasi adalah suasana khusus atau kepercayaan yang diciptakan oleh anggota suatu organisasi, dan itu tidak dapat ditiru oleh organisasi lain. Budaya organisasi juga merupakan prinsip perilaku dan harapan yang 
mempengaruhi interaksi dan kerja sama antara individu, kelompok, dan tim dalam proses melaksanakan tujuan organisasi.

Universitas yang memiliki budaya sesuai dengan strategi organisasi dan memiliki kemampuan untuk meningkatkan komitmen tenaga pengajar dan karyawan lainnya akan menjadi organisasi pembelajaran yang baik. Ketika dosen menggambarkan budaya organisasi mereka, mereka cenderung menggambarkan ciri-ciri budaya rasional, hierarkis, kelompok, dan edukatif. Dalam penelitian ini budaya didefinisikan sebagai nilainilai bersama, peraturan, prinsip perilaku, dan harapan yang memengaruhi interaksi dan kerja sama antara individu, kelompok, dan tim dalam proses melaksanakan tujuan organisasi..

\section{Kemampuan Kerja}

As'ad (2000) mendefinisikan kemampuan sebagai unsur yang melekat dalam karakteristik seseorang seperti intelegensi, kompetensi, dan kapasitas yang dimaksimalkan untuk menyelesaikan berbagai macam tanggung jawab yang telah diberikan oleh perusahaan. Seorang manusia yang memiliki kemampuan yang mumpuni memiliki potensi untuk bertindak, berpengaruh terhadap orang lain dan kekuatan tersebut bersifat stabil (konsisten). Kemampuan kerja merupakan konsep komprehensif yang mencakup dimensi fisik, mental, dan sosial (Ludvigson, Svensson, dan Alexanderson, 2006). Kemampuan kerja setidaknya harus ditinjau dari perspektif yang luas dan kaitannya dengan tuntutan pekerjaan yang aktual.

\section{Komitmen}

Karyawan yang memiliki keterlibatan (engagement) kuat cenderung memiliki komitmen tinggi pada organisasi mereka, dan ini memberikan perusahaan keunggulan kompetitif yang krusial - termasuk produktivitas kerja yang lebih tinggi. Dengan kata lain, hampir semua organisasi menyadari ini dan telah berinvestasi dalam kebijakan dan praktik yang mendorong keterlibatan dan komitmen terhadap tenaga kerja mereka. Beberapa ahli mendefinisikan komitmen sebagai keinginan untuk tetap bertahan (stay) dalam perilaku, dan ketidakinginan untuk berpaling dari rencana, atau seringkali karena mereka memiliki rasa tanggung jawab untuk tetap berada di jalur (Abrahamson et al., 1984; Cohen, 2003). Orang-orang secara bersamaan berkomitmen pada banyak entitas, seperti lembaga ekonomi, pendidikan, keluarga, politik dan agama. Mereka juga berkomitmen pada individu tertentu, termasuk pasangan mereka, anak-anak, orang tua dan saudara kandung mereka, serta kepada majikan, rekan kerja, pengawas, dan pelanggan mereka (Meyer et al., 2004).

\section{Kinerja Dosen}

Kinerja adalah hasil dari perilaku manusia yang merupakan faktor penting untuk mengevaluasi efektivitas kerja individu (Saetang dan Sulumnad, 2010). Dengan demikian, Keberhasilan atau kegagalan suatu organisasi tergantung pada kinerja pekerjaan individu dalam organisasi itu. Kinerja adalah faktor penting untuk peningkatan organisasi yang lebih baik. Dessler (2013) menyatakan bahwa untuk dapat mengevaluasi kinerja seseorang (dosen), terdapat enam metode yang dapat diterapkan yaitu: (1) penilaian dilakukan oleh ketua program studi (pimpinan) terkait, (2) penilaian dengan menggunakan justifikasi teman kerja sesama dosen, (3) penilaian yang didasarkan pada komisi penilai (BPM), (4) penilaian diri (self assesment), (5) penilaian yang dilakukan oleh mahasiswa, dan (6) umpan balik (feedback). Dalam penelitian ini penilaian kinerja dosen dilakukan oleh dosen itu sendiri. 


\section{METODE PENELITIAN}

\section{Lokasi dan Waktu}

Penelitian ini mengambil obyek pada Perguruan Tinggi di Kabupaten Maros, sedangkan periode pengumpulan data selama tiga bulan (September, Oktober dan November 2018).

\section{Jenis dan Sumber Data}

Studi ini memanfaatkan dua jenis data yaitu 1) data kuantitatif yaitu data yang berbentuk bilangan atau angka yang dapat diukur, diolah atau dianalisis dengan menerapkan teknik statistik, 2) data kualitatif merupakan data redaksional (teks), yang diperoleh melalui serangkaian teknik pengumpulan data misalnya wawancara terstruktur atau tidak terstruktur, analisis konten, fokus grup diskusi (FGD) dan observasi.

Data yang diperoleh dalam penelitian ini bersumber dari 1) data primer merupakan data yang didapatkan langsung melalui obyek/ responden/ informan yang diteliti. Beberapa metode yang umum diterapkan ialah wawancara langsung dan observasi dan hasil angket dari dosen; 2) data sekunder ialah data yang diperoleh dari berbagai sumber yang merupakan pendukung dari penelitian, misalnya dokumentasi/ tulisan (buku, laporan, dan artikel jurnal), dan informasi dari pihak yang berhubungan dengan konsep yang sedang ditelusuri.

\section{Metode Pengumpulan Data}

1. Observasi ialah metode penelusuran langsung budaya kerja, kemampuan dan komitmen, dan kinerja dosen di Kabupaten Maros.

2. Kuisioner (angket) yaitu proses pengumpulan data dengan menggunakan sejumlah daftar pertanyaan (atau pernyataan) tertulis yang kemudian disebar secara proporsional kepada responden untuk mendapatkan data mentah yang valid dan reliabel.

3. Wawancaraadalah dialog secara langsung untuk menggali data dari informan yang telah dipilih melalui serangkaian seleksi, dan relevan dengan studi.

\section{Populasi dan Sampel}

Populasi penelitian yang ditetapkan adalah keseluruhan dosen di Kabupaten Maros yang berjumlah 191 orang. Pengambilan sampel menggunakan rumus Slovin dengan margin error $5 \%$, sehingga jumlah resonden yang dianggap sebagai representasi keseluruhan adalah 129 orang (Sugiyono, 2013).

\section{HASIL DAN PEMBAHASAN}

Berdasarkan hasil pengukuran ditemukan variabel budaya berpengaruh positif dan signifikan terhadap kinerja dosen di Kabupaten Maros. Artinya, semakin baik penerapan budaya, maka akan semakin tinggi pula kinerja dosen yang bersangkutan, dan sebaliknya pula, jika budaya kerja yang produktif semakin rendah dalam melaksanakan tugasnya, maka kinerja dosen menurun. Asumsi faktor lain yang memengaruhi kinerja tetap konstan, dengan koefisien pengaruh sebesar 0,228, t-hitung 3,055 dan probabilitas $0,003<0.05$.

Jika setiap dosen pada Perguruan Tinggi di Kabupaten Maros mampu meningkatkan dan menanamkan dalam dirinya bahwa budaya kerja harus diterapkan dalam Perguruan Tinggi demi kepentingan Perguruan Tinggi dan untuk diri sendiri sebagai dosen dalam rangka mengangkat harta dan martabatnya sebagai pengajar, peneliti dan pengabdi kepada masyarakat, maka peningkatan kinerja baik secara individu maupun kelompok berpotensi dimaksimalkan di segala level. Penelitian ini berkontribusi dalam meningkatkan kinerja dosen, oleh karena itu, masih perlu dilakukan upaya 
peningkatan budaya kerja dosen di Perguruan dalam sikap terhadap pekerjaan dan waktu saat melaksanakan Tridarma. Temuan ini konsisten dengan studi Setiawati (2011) dan Setyadi (2013) yang telah membuktikan peran budaya kerja terhadap kinerja dosen.

Variabel kemampuan memiliki pengaruh positif dan signifikan terhadap kinerja dosen di Kabupaten Maros. Artinya, semakin tinggi kemampuan kerja yang dimiliki dosen dalam melaksanakan tugas, maka kinerja dosen akan semakin meningkat. Sebaliknya, semakin rendah kemampuan dan kapasitas dosen, maka kinerja dosen akan semakin memburuk. Asumsi faktor lain yang mempengaruhi kinerja tetap konstan, dengan koefisien regresi sebesar 0,322, dan $t$ hitung 4,003 dan probabilitas 0,000 $<0,05$. Penelitian ini telah membuktikan bahwa keterampilan dosen dalam memenuhi kewajibannya ternyata berimpilkasi positif pada kinerja. Hal ini sejalan dengan pendapat Anggraeni (2008) dalam pencapaian target, kualitas sumber daya manusia memegang peranan yang esensial. Dosen bekerja berdasarkan dengan apa tugas pokok dan tanggung jawab yang diperlukan seorang dosen. Tingkat keterampilan yang matang serta pola pikir yang sistematis dalam memecahkan segala permasalahan seyogyanya dimiliki oleh dosen. Beberapa di antaranya ialah pengetahuan, keahlian, sikap, dan perilaku dalam menyelesaikan tugas yang telah dibebankan kepadanya. Hasil ini sejalan dengan temuan Andriyani (2010) dan Anggraeni (2008) yang menyatakan bahwa faktor kemampuan berpengaruh positif dan signifikan terhadap kinerja dosen. Implikasi praktis dan implementasi hasil penelitian dapat meningkatkan kinerja terutama dalam memenuhi tugas Tridharma perguruan tinggi, dan mengembangkan kemampuan kerjanya melalui program pendidikan dan pelatihan untuk pengembangan aspek intelektualitas dan kepribadian.

Variabel komitmen individu menunjukkan pengaruh positif dan signifikan terhadap kinerja dosen di Kabupaten Maros. Ini berarti bahwa semakin eratnya komitmen dosen terhadap institusi sendiri, maka semakin meningkat kinerja dosen yang bersangkutan, demikian pula jika komitmen dosen terhadap perguruan tinggi rendah, maka akan semakin rendah kinerja dosen bersangkutan. Asumsi faktor lain yang memengaruhi kinerja tetap konstan, dengan koefisien pengaruh sebesar 0,301 t-hitung 3,502 dan probabilitas $0,001<0,05$. Besarnya pengaruh komitmen kerja terhadap peningkatan kinerja dosen disebabkan karena besarnya keinginan setiap dosen untuk tetap berada pada perguruan tinggi dan meningkatkan perguruan tinggi di Kabupaten Maros. Implikasi dari hasil penelitian ini, bahwa komitmen dosen amatlah penting artinya dapat mendorong upaya mereka untuk tetap melaksanakan tugasnya pada Perguruan tinggi di Kabupaten Maros. Dalam hal ini komitmen kerja dapat dilaksanakan pada Perguruan Tinggi di Kabupaten Maros melalui pemberian motivasi kerja dan pemenuhan kebutuhan dosen baik kebutuhan material melalui non material, serta komitmen kerja ini dipengaruhi pula karakteristik pekerjaan, karakteristik struktur organisasi Perguruan Tinggi dan pengetahuan dan pengalaman kerja. Hasil ini mendukung penelitian sebelumnya yaitu Simbolon (2010). Namun, temuan ini berlawanan dengan Murdiyani (2010) yang tidak menemukan korelasi signifikan antara kedua variabel.

Berdasarkan hasil penelitian secara simultan, variabel budaya kerja (X1), kemampuan (X2) dan komitmen (X3) memiliki efek positif dan signifikan terhadap kinerja dosen perguruan tinggi di kabupaten Maros. Hasil ini dideskripsikan dalam Tabel hasil analisis regresi berganda bahwa Budaya kerja (X1) dengan koefisien regresi 0,228 dan kemampuan dengan regresi 0,322 dan komitmen (X3) dengan koefisien regresi 0,301. Mengacu pada persamaan regresi tersebut menunjukkan bahwa variabel kemampuan (X2) merupakan prediktor terbesar terhadap kinerja dosen di kabupaten Maros. Hal ini dipandang sejalan dengan tugas utama dosen yang terdapat dalam Tridarma yang terdiri dari pendidikan dan pengajaran, penelitian, dan pengabdian kepada masyarakat. Tugas dosen yang terdiri atas tridarma perguruan tinggi dalam penelitian ini lebih dominan kepada tugas dosen di bidang pendidikan dan pengajaran. 


\section{E. KESIMPULAN}

Ketiga variabel independen (budaya kerja, kemampuan dan komitmen) secara bersama-sama memiliki efek signifikan terhadap kinerja dosen perguruan tinggi di kabupaten Maros. Secara parsial, ketiga variabel tersebut memberikan dampak positif dan signifikan terhadap kinerja dosen di Kabupaten Maros. Variabel kemampuan (X2) merupakan anteseden dominan dalam memberikan efek signifikan terhadap kinerja dosen. Dalam melaksanakan pendidikan dan pengajaran, dosen lebih banyak meluangkan waktu dan pikirannya jika dibandingkan dengan dengan variabel budaya kerja dan komitmen.

\section{DAFTAR PUSTAKA}

Abrahamson, M., \& Anderson, W. P. (1984). People's commitments to institutions. Social Psychology Quarterly, 47, 371-381.

Achmad Rozi, El Eroy ,A, 2010 . Budaya kerja,arozieleroy.wordpress.com

Andriyani, Titi , 2010, Pengaruh karakteristik biografi dan kemampuan kerja individual dosen terhadap kinerja Dosen . Jurnal Politeknik negeri Sriwijaya

Anggraeni,Nenny, 2008. Pengaruh Kemampuan dan Motivasi terhadap Kinerja Pegawai Pada Sekolah Tinggi Seni Indonesia (STSI). Jurnal Bandung.

Armstrong, Michael. (2016). Armstong's Handbook of Management and Leadership for $H R$, 4th ed. Philadelphia: Kogan Page Limited

As'ad ,Moh, 2000. Psikologi Industri, Liberty: Yogyakarta.

Asnul Madura, 2000. Kepemimpinan Dalam Implementasi Organisasi. Penerbit AndiYogyakarta

Bontis, N. (1996), "There's a price on your head: managing intellectual capital strategically", Ivey Business Quarterly, Vol. 60 No. 94, pp. 40-8.

Cai, Y., Lin, C. Theory and Practice on Teacher Performance Evaluation. Front. Educ. China 1, 29-39 (2006). https://doi.org/10.1007/s11516-005-0004-x.

Cohen, A. (2003). Multiple commitments in the workplace: An integrative approach. Mahwah, NJ: Lawrence Erlbaum Associates

Daft, R. L. 2003. Organization Theory and Design, Southwestern College Publishing; Ohio.

Dessler. 2013. Manajemen Sumber Daya Manusia Human Resources, Jilid 2. Prenhalindo:Jakarta.

Handoko , 2002 Manajemen SDM,Penerbit Gramedia Pustaka. Yogyakarta

Hasibuan, Malayu SP, 2008. Manajemen Sumber Daya Manusia, Edisi revisi. Jakarta. PT. Bumi Karsa.

Indriyani, Henni dan Muhammadinah. 2010. Pengaruh Kemampuan dan Jaya Disiplin Kerja PT. Rizki Kurnia Palembang.

Kadim, A., Sunardi, N., Lesmana, R., \& Sutarman, A. (2019). Revitalisasi Fungsi Masjid Sebagai Pusat Penguatan Manajemen Peternak Sapi Rakyat melalui Lembaga Pemberdayaan Masyarakat Terpadu (LEMPERMADU).(Studi Kasus di Masjid Ainul Yaqin Kel. Jontlak, Kec. Praya, Kab. Lombok Tengah, Provinsi Nusa Tenggara Barat). Jurnal Abdi Masyarakat Humanis, 1(1).

Khairuzzaman, et al. (2014). The impact of human resource management practices on performance. The TQM Journal, Vol. 26, Iss 2 pp. 125 -142.

Lesmana, R. (2019). Pengaruh Kualitas Produk Dan Kualitas Pelayanan Terhadap Kepuasan Konsumen Pt. Radekatama Piranti Nusa. Jurnal Pemasaran Kompetitif, 2(2), 115-129. 
Lesmana, R., \& Ayu, S. D. (2019). Pengaruh Kualitas Produk Dan Citra Merek Terhadap Keputusan Pembelian Kosmetik Wardah Pt Paragon Tehnology And Innovation. Jurnal Pemasaran Kompetitif, 2(3), 59-72.

Ludvigson M, Svensson T, Alexanderson K 2006. The concept of work ability: A literature review. Arbete och Hälsa.

Marihot Tua Efendi,Hariandja. 2002. Manajemen Sumber Daya Manusia. Jakarta: PT. Bumi Aksara.

Mathis, Robert L dan John H Jackson .2002 Humen Resource management, 10th edition.Thomson South Westerm, United State of America.

Meyer, J. P., Becker, T. E., \& Vandenberghe, C. (2004). Employee commitment and motivation: A conceptual analysis and integrative model. Journal of Applied Psychology, 89, 991-1007.

Murdiyani, Hetty, 2010. Pengaruh Beban kerja, Kepuasan kerja dan Komitmen Organisasi Terhadap Kinerja Dosen Tetap.Tesis Pasca Sarjana. Universitas Sebelas Maret Surakarta.

Narsim, 2008. Pengaruh Motivasi, Kemampuan Kerja dan Tingkat Pendidikan Format Terhadap Parawisata Di Dinas Parawisata Kabupaten Cilacap. Tesis Program Studi Magister Parawisata Pasca Sarjana ( STEPARI) Semarang.

Nawawi, Handari, 2000.Perencanaan SDM Untuk organisasi profil dan Kompetitif. Gajah Mada University press, Yogyakarta.

Nenny, Anggraeni. 2008. Pengaruh Kemampuan dan Motivasi terhadap Kinerja Pegawai pada Sekolah Tinggi Seni Indonesia (STSI) .Jurnal.

Osborn dan Plastrik, 2002 .Manajemen Sumber Daya Manusia, BPFE.Yogyakarta,

Parlindungan, Simbolon, A, 2010 .Pengaruh Komitmen Kerja terhadap Kinerja Dosen di Jurusan Administrasi yang Niaga Politeknik Negeri Medan.Jurnal.

Prabu Mangkunegara, Anwar, 2010. Manajemen Sumber Daya Manusia Perusahaan.Bandung.

Rivai, Veithzal. 2004. Manajemen Sumber Daya Manusia untuk Perusahaan. Dari Teori ke Praktek. Jakarta: PT. Raja Grafindo Persada

Saetang, Jarunee; Sulumnad, Kodchakorn; Thampitak, Piyarat and Sungkaew, Thoungtong (2010). Factors Affecting Perceived Job Performances among Staff :A Case Study of Ban Karuna Juvenile Vocational Training Centre for Boys. The Journal of Behavioural Science, Vol.5, No. 1, pp. $33-45$.

Sangadji, E.M., \& Sopiah (2013). The Effect of Organizational Culture On Lecturers' Job Satisfaction and Performance (A Research in Muhammadiyah University throughout East Java).

Santosa, Purbayu Budi dan Ashari, 2005. Analisis Statistik dengan Microsoft Excel \& SPSS. Penerbit Andi, Yogyakarta.

Saranya, K. 2014. Influence of Jo b Satisf action on Employees' Performance - A General Perspective, International Journal on Global Business Management and Research, Vol.2, Iss 2.

Sarnawiah. 2013. Beberapa Faktor Mempengaruhi Nilai Evaluasi kinerja Dosen Dengan Menggunakan Pendekatan Multirater.UNHAS, tesis tidak dipublikasikan.

Setiawati,Tati, 2011 .Pengaruh Budaya kerja Terhadap Kinerja Dosen. Jurnal Universitas Pendidikan Indonesia

Setyadi ,R, 2013 . Pengaruh Budaya kerja terhadap Kinerja Dosen.Jurnal

Simamora,H, 2001. Manajemen Sumber Daya Manusia, Edisi Kedua Penerbit STIE YKPN, Yogyakarta

Subramony, M. (2006). Why Organizations Select some Human Resource Management Practices and Reject Others: An Exploration of Rationales. Human Resource Management, 45, 195-210.

Sugiyono. (2013). Metode Penelitian Manajemen. Bandung: Alfabeta 
Sunardi, N., Lesmana, R., \& Tumanggor, M. (2018). Implementasi Manajemen Dalam Meningkatkan Iman Dan Taqwa Masyarakat Dusun Panyeredan, Cimanggu, Cisalak, Subang-Jawa Barat. Jurnal Pengabdian Dharma Laksana, 1(1), 131-140.

Sunardi, N., Lesmana, R., Tumanggor, M., \& Kadim, A. (2019). Implementasi IImu Manajemen dalam Mewujudkan Pembangunan Masjid Raya Abdul Kadim, Yayasan Ar-Rohim, Kab. Musi Banyuasin, Propinsi Sumatra Selatan. Jurnal Abdi Masyarakat Humanis, 1(1).

Sutrisno, Edy, 2009. Manajemen Sumber Daya Manusia, Kencana, Jakarta.

Warsihna, Jaka, Penelitian Budaya kerja dan kerjasama Tim. Seri Modul JF-PTP ,KEMDIKBUD

Wibowo, 2013. Manajemen Kinerja, Rajawali . Jakarta.

Wursanto, 2004 Manajemen Keempat Kepegawaian. Cetakan Penerbit Kenasiar, Jakarta.

Yiing, L. H., dan Ahmad, K. Z. B. 2009. The moderating effects of organizational culture on the relationships between leadership behavior and organizational commitment and between organizational commitment and job satisfaction and performance, Leadership and Organization Development Journal, 30(1), pp. 53-86. 